\author{
M.C. Sbernardori \\ V. Mazzarello \\ P. Bandiera \\ A. Pirino \\ C. Fabbriciani \\ A. Montella
}

\section{Scanning electron microscopic study of dermatoglyphics in carpal tunnel syndrome}

Received: 15 January 2005

Accepted: 20 November 2005

Published online: 25 September 2006
M.C. Sbernardori (凶) • C. Fabbriciani Department of Orthopaedics

University of Sassari

Sassari, Italy

E-mail: mcsbernardori@tiscalinet.it

V. Mazzarello • P. Bandiera • A. Pirino

A. Montella

Department of Biomedical Sciences

Division of Human Anatomy

University of Sassari

Sassari, Italy

\begin{abstract}
The dermatoglyphics of the volar tip of the thumb and index finger of 20 patients in the first stage of carpal tunnel syndrome (CTS) without electromyographically detectable thenar impairment were examined by scanning electron microscopy with the aim of analysing its threedimensional features. In comparison with 20 healthy controls, only the central portion of the thumb and the central, medial and lateral portions of the index finger showed clear modifications. A low grade of hydrosis, confirmed by morphometrical measurements, was present in all pathological samples. Even the dermal ridges differed from the controls: in the pathological digits these were less flattened, more elevated and
\end{abstract}

decreased in length, and the dermatoglyphics were less evident. The keratinocytes were identified on the dermal ridges in groups of 4-5 elements, with abundant exfoliation and numerous sweat pores which were irregular in size but had an increased diameter, probably due to compression of the autonomic fibers contained in the median nerve. To sum up, by using scanning electron microscopy, this study documented dermal alterations that occur in the thumb and index finger during the initial stages of CTS and that may be features of autonomic neuropathy.

Key words Carpal tunnel syndrome • Dermatoglyphics $\cdot$ Scanning electron microscope

\section{Introduction}

The volar surface of human hands and feet is composed of ridges and furrows that constitute a unique pattern named by Cummins in 1926 as "dermatoglyphics". These differing patterns of epidermal ridges are important in medicolegal diagnosis and in congenital malformations [1], and these reasons many aspects of dermatoglyphics have been investigated [2]. For this reason too, the embryological development of epidermal ridges has been the object of several studies [3-5] which have described perfectly, step by step, its embryogenesis up to the point in which its definitive differentiation occurs by the nineteenth week [6]. Histological studies of the dermatoglyphics have been conducted using different methods and techniques. Using scanning electron microscopy it has been possible to observe the surface anatomy of dermatoglyphics and even the dermal-epidermal junctions [7, 8] and, recently, the basal surface of the epidermis in human fingers [9].

With regard to carpal tunnel syndrome (CTS), some authors have been described the presence of ulceration [10-12], nail dystrophy [13] and ischemic skin lesions [14] in patients suffering from an advanced stage of disease, sometimes associated with other diseases [12]. 
However, no study exists in the literature, particularly one undertaken by scanning electron microscopy (SEM), regarding the pattern of dermal ridges in patients affected by CTS. Therefore, we used SEM to document the epidermal modifications of the fingertip of the thumb and index finger in patients affected by CTS during the first stage of median nerve compression.

\section{Materials and methods}

The study enrolled 20 patients with CTS and 20 normal controls. The patients' mean age was 42.3 years; 16 of them were female while 4 were male. Every patient had a clinical history of CTS with nocturnal paresthesie in the territory of the median nerve without thenar muscle weakness (as documented by electrophysiological studies). At the date of the examination none of the patients showed symptoms of other associated diseases. The control group consisted of 20 volunteers (14 women) of mean age 43.8 years. The control subjects were recruited among medical staff choising who had never showed carpal tunnel symptoms.

From each study subject, 15 samples were taken from the index finger and 5 were taken from the thumb. Samples were obtained from the thumb and index finger after a hand wash with neutral soap lasting $4 \mathrm{~min}$, followed by $30 \mathrm{~min}$ acclimatization in a room at $23^{\circ}$ $\mathrm{C}$ and $60 \%$ humidity assured by Toshiba RAS 4M27YAV-E conditioner. Dermal copies were obtained using a silicone resin and the contrareplicas were prepared using araldite. The specimens were subsequently coated with a layer of gold. Finally, all specimens were observed under a Zeiss 960 A scanning electron microscope and submitted to a hystomorphometric and statistical analysis.

\section{Results}

The dermatoglyphics of the volar portion of thumb and index finger were assessed by SEM in 20 patients with carpal tunnel syndrome (CTS) and in 20 healthy controls. In each of the controls, the surface of the examined digit was covered by a dermo-epidermal layer composed of ridges and furrows that constitute dermatoglyphics (data not shown). The loops, whols and triradii of the fingerprints were cleary evident. The control specimens showed a moderate hydrosis on the epidermal surface with small beads of sweat, regular in shape, which were only located in an orderly manner in the furrows between the dermal ridges. The horny cells were globular in shape, with an ordinary exfoliation in fragments in which four or five elements were detected. Furthermore, the pores of the sweat glands resembled holes found on top of the dermic ridges and distributed in an olderly manner.

In the pathological samples, interesting modifications were detected in the central portion of the volar surface of the tip of the thumb (Fig. 1) and in the central, medial and lateral portions of the index finger. The first observation to be detected was a low grade of hydrosis in these areas (Fig. 2), confirmed by histomorphometrical measurements. In fact, sweat beads covered $11.61 \%$ of the total skin area in control samples but only $6.45 \%$ in pathological samples (Table 1). No noticeable differences were detected regarding shape and size of the beads of sweat (Fig. 3a, b). Moreover in CTS samples the dermal ridges were less flattened and more elevated

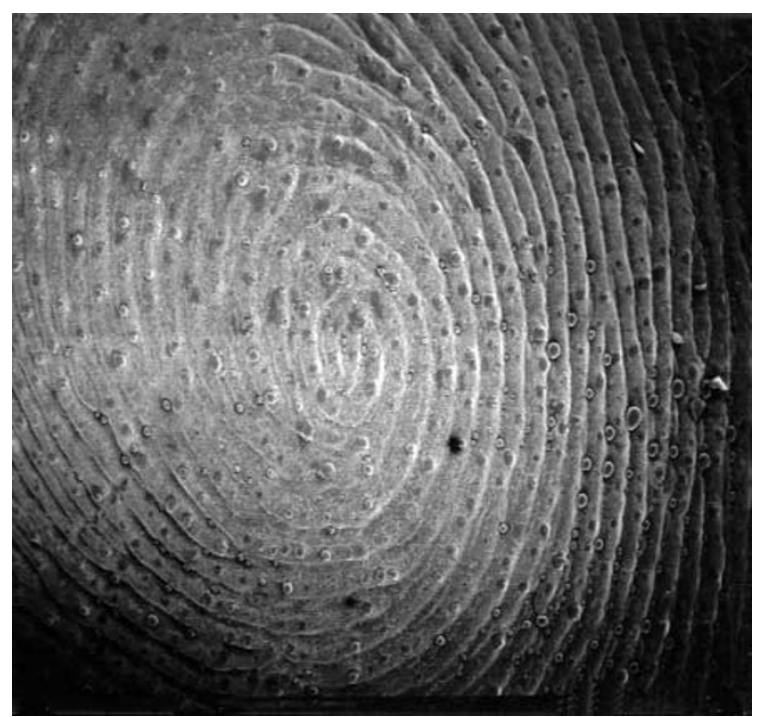

Fig. 1 Central portion of the volar surface of the tip of the thumb in pathological sample. (Scanning electron microscope. Original magnification $\mathrm{x}$ 9)

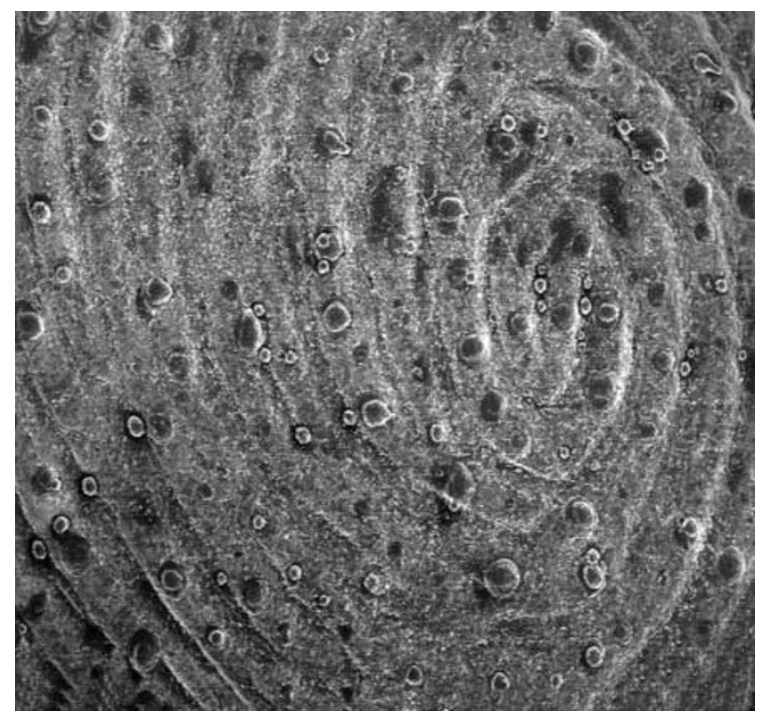

Fig. 2 A low grade of hydrosis can be detected on the epidermal surface in CTS. (Scanning electron microscope. Original magnification $\mathrm{x} 20$ ) 
Table 1 Histomorphometric analysis of the volar surfaces of the thumb (5 samples per subject) and index finger ( 15 samples per subject), in 20 patients with carpal tunnel syndrome (CTS) and in 20 healthy controls

\begin{tabular}{lrr}
\hline & CTS $(\mathrm{n}=20)$ & Control $(\mathrm{n}=20)$ \\
\hline Sweat beads & & \\
$\quad$ Area, $\mu^{2}$ & $19.4(14.2)$ & $19.3(10.5)$ \\
$\quad$ Skin area covered, \% & 6.45 & 11.61 \\
Dermal ridges & & \\
$\quad$ Length, $\mu$ & $395.6(53.8)$ & $529.7(44.4)$ \\
Pores & & \\
$\quad$ Area, $\mu^{2}$ & $20.7(8.7)$ & $12.6(4.7)$ \\
$\quad$ Skin area covered, \% & 6.96 & 4.96 \\
\hline
\end{tabular}
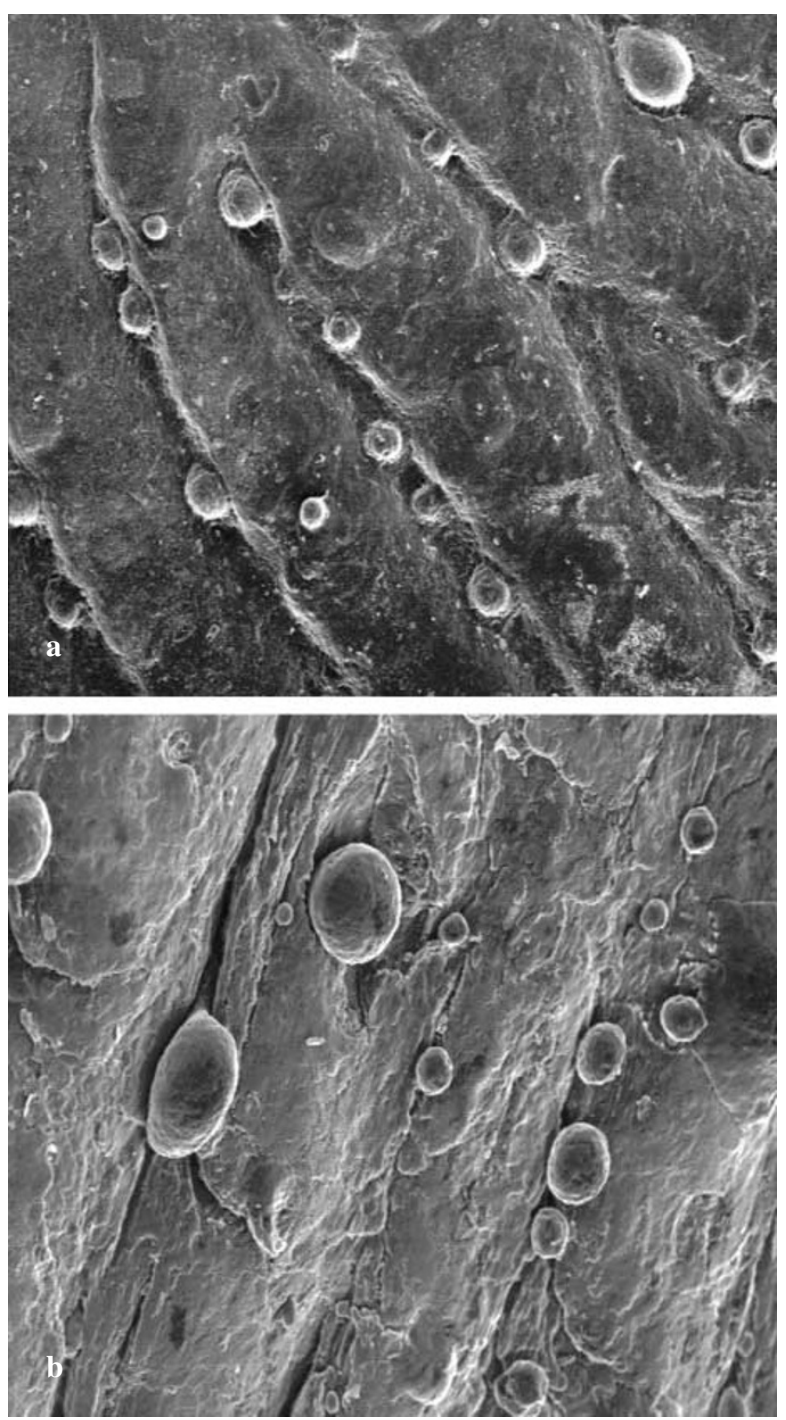

Fig. 3a, b Beads of sweat in the furrows and on top of the epidermal ridges. a CTS. (Scanning electron microscope. Original magnification x 50). b Control (Scanning electron microscope. Original magnification $\mathrm{x} 10$ )
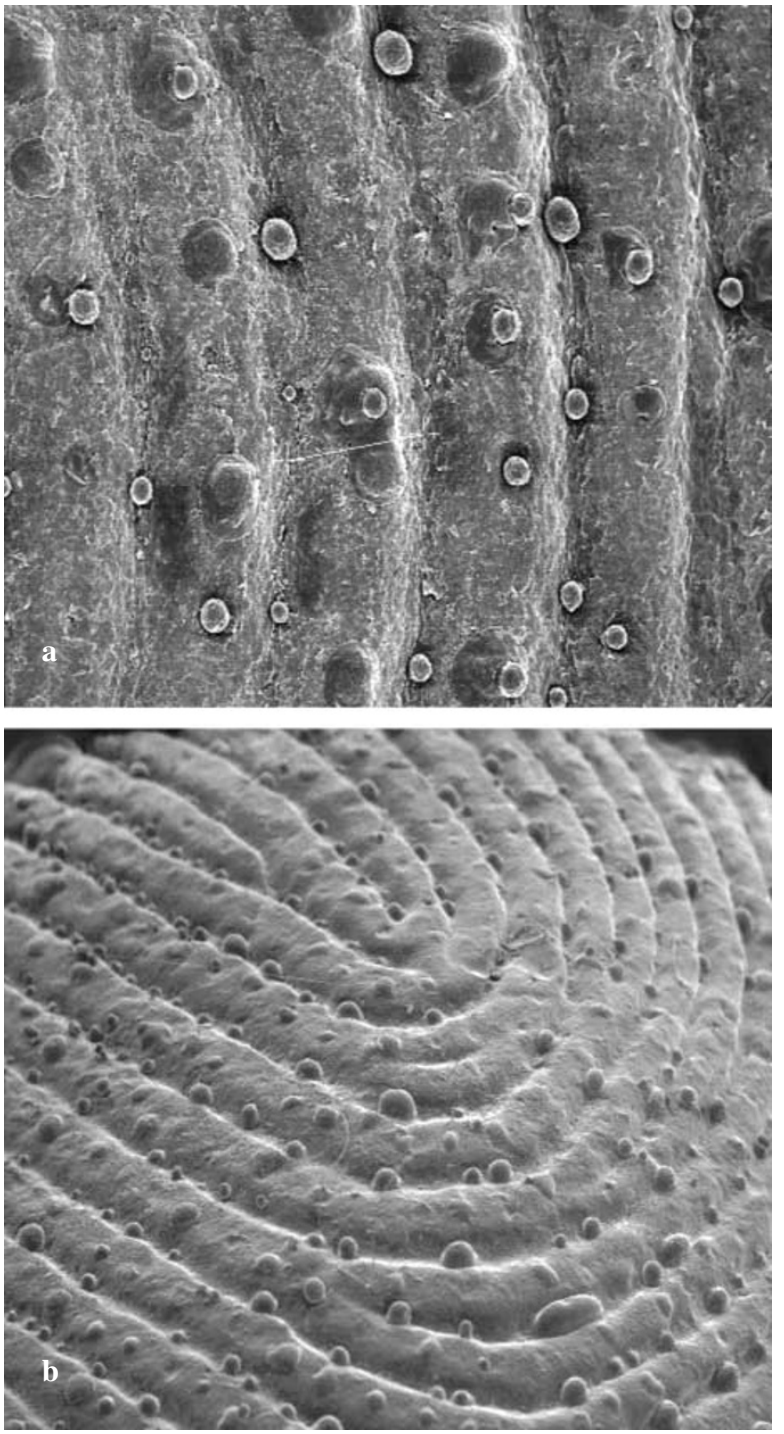

Fig. 4a, $b$ Dermal ridges and intercalated furrows a In CTS, these appear to be more evident. (Scanning electron microscope. Original magnification x 50). b Control sample (Scanning electron microscope. Original magnification x 20)

(Fig. 4a, b); the dermal ridges in pathological samples were also shorter in length (Table 1).

The pattern of dermatoglyphics did not change in CTS, but was more marked. The horny cells were more flattened and showed disarranged exfoliation (Fig. 5). Regarding the corkscrew-like canal of the sweat glands which open in the keratinized layer (Fig. 6), in CTS they were situated on the top of dermal ridges but the diameters were not homogeneous. Furthermore, morphometric analysis of the pores revealed a larger diameter in the pathological samples (Table 1). In pathological samples, $93.04 \%$ of the skin area was free from pores in comparison to $95.04 \%$ in normal samples. 


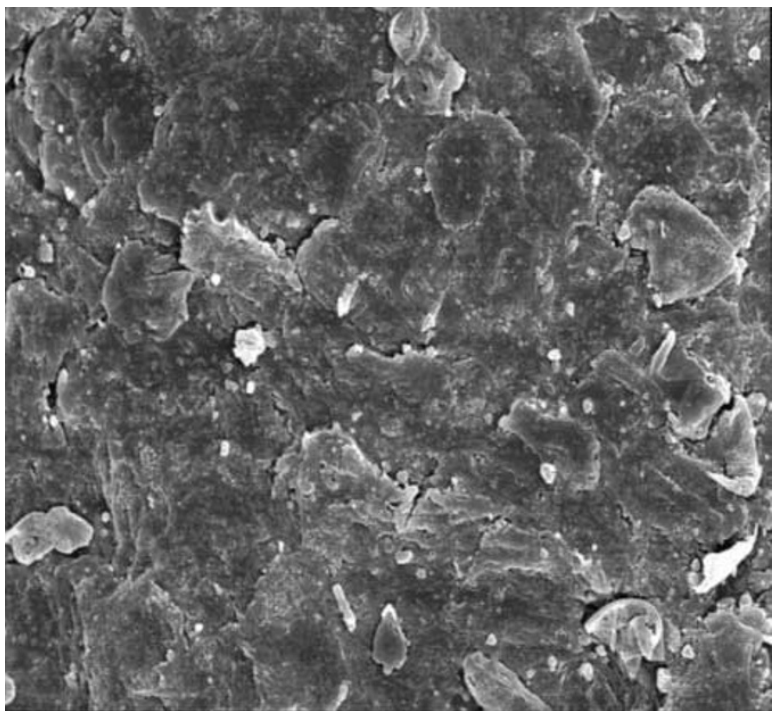

Fig. 5 The disarranged exfoliation pattern of the epidermal surface in CTS. (Scanning electron microscope. Original magnification $\mathrm{x}$ 500)

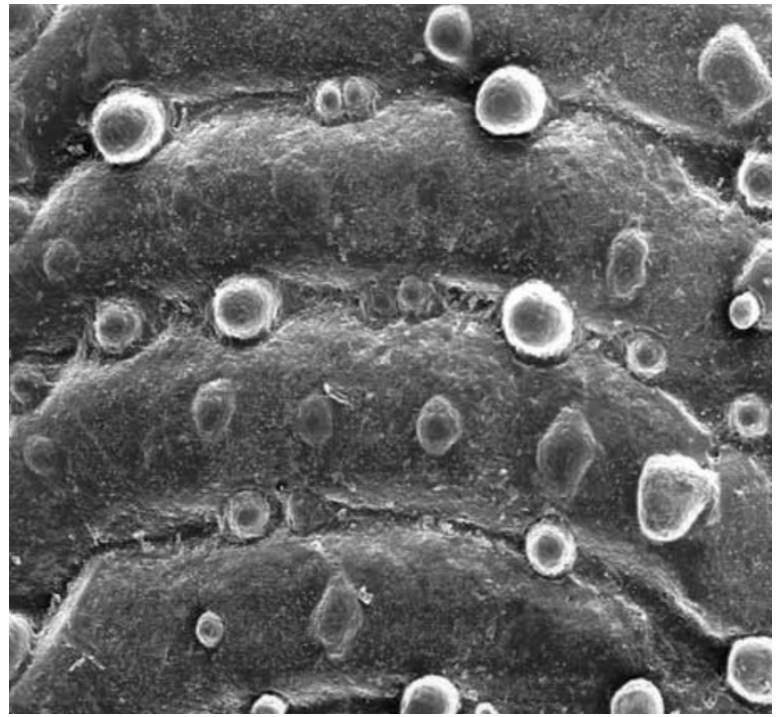

Fig. 6 The pore diameters are not homogeneous, showing a partial loss of the regulation mechanism (Scanning electron microscope. Original magnification x 50)

\section{Discussion}

The importance of innervation for good dermal-epidermal pattern of the skin is well known. So too is how, after lesions or interruptions of the nerves, the skin can suffer until there is complete cutaneous atrophia, anhydrosis and consequently ulceration or blistering $[11,13$,
15]. Some authors have described the presence of cutaneous alterations such as ulceration and blistering occurring in the final stage of median nerve compression [10, $11,13,14]$, sometimes associated with other diseases $[11,12]$. However, until now no studies have correlated the first stage of nerve compression in the CTS with modifications in the skin of the digits involved. This study, undertaken with scanning electron microscopy, revealed that important dermal-epidermal modifications occur just before the onset of any eletrophysiologically detectable thenar motor impairment. All components of the volar digital skin surface underwent early modifications even if the global pattern of dermatoglyphics (loops, whorls and triradii of every patient) did not change in configuration, and so there are consequently no correlating medicolegal problems.

The modifications of the surface anatomy of the keratinized layer, as detected by SEM, are firstly, a general decrease of length of the dermal ridges associated with a low grade of hydrosis; secondly, an increase in exfoliation; and thirdly, irregular activation of the sweat glands. These sweat glands show dilated pores which may be trying to balance the low grade of hydrosis. These modifications may represent the first cutaneous alterations that cause ulcerations and blisters, as previously detected by several authors $[10,11,13,14]$ in the advanced phases of median nerve compression. Comparison with other neuropathic diseases of the autonomic nervous system (such as Sudek disease) suggests that these modifications may also be due to an autonomic neuropathy. This may explain part of the symptomatology that patients classically refer to as a sensation of tenderness, swelling and perspiration, which are all associated with a decrease of sensitivity and capacity of fine pinch.

To sum up, the detection of early structural modifications of the skin of the volar tip of the thumb and index finger in patients affected by CTS proves that from the very first stage of median nerve compression (not associated with other disease) there is involvement of the autonomic fibers carried by the median nerve through the carpal tunnel. This autonomic neuropathy may explain part of the symptomatology referred to by patients and may provide other reasons for not delaying surgical decompression of the median nerve. In addition, it may be necessary to reconsider the structures involved in CTS: not only the median nerve, as classically described, and the thenar muscles, but also the epidermal surface.

No benefits in any form have been received or will be received from a commercial party related directly or indirectly to the subject of this article and the manuscript has been seen and approved by all authors. 


\section{References}

1. Watanabe $\mathrm{K}$, Nakamura R, Miura T (1994) Palmar dermatoglyphics in congenital hand anomalies. J Hand Surg Am 19:961-967

2. Penrose LS (1965) Dermatoglyphic topology. Nature 6:544-546

3. Penrose LS, Ohara PT (1973) The development of the epidermal ridges. $\mathbf{J}$ Med Genetics 10:201-208

4. Okajima M (1975) Development of dermal ridges in the fetus. J Med Genetics 12:243-250

5. Okajima M, Newell-Morris L (1988) Development of dermal ridges in the volar skin of fetal pigtailed macaques (Macaca nemestina). Am J Anat 183:323-337

6. Mulvihill JJ, Smith DW (1969) The genesis of dermatoglyphics. J Pediatrics 75:579-589
7. Kawabe TT, Maccallum DK, Lillie J (1985) Variation in basement membrane topography in human thick skin. Anat Record 211:142-148

8. Misumi Y, Akiyoshi T (1984) Scanning electron microscopic structure of the fingerprint as related to the dermal surface. Anat Record 208:49-55

9. Yamada N, Kashima Y, Inouè T (1996) Scanning electron microscopy of the basal surface of the epidermis of human digits. Acta Anatomica 155:242-248

10. Fritz TM, Burg G, Boni M (2000) Carpal tunnel syndrome with ulcerous skin lesions. Dermatology 201:165-167

11. Cox NH, Large DM, Paterson WD, Ive FA (1992) Blisters, ulceration and autonomic neuropathy in carpal tunnel syndrome. Br J Dermatol 126:611-613
12. Adoue D, Arlet PH, Giraud M, Bories P, Bonafè JL (1984) Syndrome du canal carpien avec ulcerations digitales chez un insuffisant renal en hemodialyse periodique. Ann Dermatol Venereol 111:1019-1021

13. Aratari E, Regesta G, Rebora A (1983) Carpal tunnel syndrome appearing with prominent skin symptoms. Arch Dermatol 120:517-519

14. Tosti A, Morelli R, D'Alessandro, Bassi F (1993) Carpal tunnel syndrome presenting with ischemic skin lesions, acroosteolysis, and nail changes. J Am Acad Dermatol 29:287-290

15. Chang HY, Huang IT, Chen WP (1998) Regional difference in epidermal thinning after skin denervation. Exp Neurol 154:137-145 